\title{
Comparative epidemiology of gentamicin-resistant enterobacteria: persistence of carriage and infection
}

\author{
CA HART, MARJORIE F GIBSON
}

From the Department of Medical Microbiology, University of Liverpool, Duncan Building, Royal Liverpool Hospital, Prescot Street, Liverpool L7 $8 X W$

SUMMARY During a two-year period from January 1979, 260 patients have been involved in an outbreak of carriage and infection due to gentamicin-resistant enterobacteria. We have examined the duration of carriage of such enterobacteria and have compared the carriage of Klebsiellae with that of other resistant enterobacteria.

Carriage of gentamicin-resistant enterobacteria occurred most frequently and was least sporadic in the intestinal tract. Vaginal carriage was observed in 49 out of 68 patients tested and occurred more frequently in older patients. Oral carriage was noted in $36 \%$ of patients but was more sporadic than intestinal carriage. Rates of oral carriage were greater among moribund patients. Carriage at skin sites was related to their proximity to the perineum.

Intestinal carriage of gentamicin-resistant Escherichia coli and Klebsiellae but not Klebsiella oxytoca nor Citrobacter persisted for long periods (half lives of 140 and 100 days respectively). Cessation of carriage of gentamicin-resistant Klebsiellae was due to loss of both the organism and its plasmid rather than a shedding of the plasmid.

Chronic bacteriuria with gentamicin-resistant $E$ coli and Klebsiellae (half life 180 days) but not Klebsiella oxytoca nor Citrobacter persisted for long periods.

Although there have been numerous studies on the prevalence and incidence of carriage of Klebsiellae both gentamicin-sensitive, ${ }^{12}$ and gentamicin-resistant, ${ }^{34}$ little is known of the persistence of such carriage except from anecdotal reports. ${ }^{5}$ The occurrence of resistance in enterobacteria to gentamicin is still sufficiently unusual to provide a good selective marker and greater precision can be achieved by using epidemiological tools such as serotyping, biotyping and klebecine typing. Use of these methods has permitted a comparative study on the ability of various gentamicin-resistant enterobacteria to persist in the intestinal and urinary tracts of patients.

In January 1979 a large outbreak of infection due to gentamicin-resistant enterobacteria began at the Royal Liverpool Hospital and in the two-year period until January 1981 involved 260 patients. The majority of patients (193) presented with evidence of urinary tract infections and most of these (146) occurred following the insertion of urinary catheters or following surgical manipulation of the urinary tract. The remaining patients presented with surgical

Accepted for publication 20 August 1981 wound infections (13), lower respiratory tract infections (14) and there was one case of primary bacteraemia. In addition 39 patients showed intestinal carriage in the absence of infection. Gentamicin-resistant strains of Klebsiellae, E coli, Citrobacter, Enterobacter, Proteus and Providencia have been isolated from the patients (Table 1).

Table 1 Gentamicin-resistant enterobacteria isolated from 260 patients

\begin{tabular}{lcl}
\hline Organism & No of patients* & No and types \\
\hline Klebsiella spp & 236 & 32 serotypes + 38 non-typable \\
& 41 & strains \\
E coli & 13 & 20 “API-types" \\
Enterobacter spp & 25 & 12 “API-types" \\
Citrobacter spp & 2 & 15 “API-types" \\
Proteus spp & 2 & - \\
Providencia spp & 2 & - \\
\hline
\end{tabular}

*Some patients harboured more than one gentamicin-resistant strain.

Cross-infection and cross-contamination occurred readily with gentamicin-resistant Klebsiellae but was not observed for the other gentamicin-resistant strains. This finding may be related to the relative 
ability of the various enterobacteria to survive on skin and drying. ${ }^{7}$ However, it has been shown that the intestinal tract provides a reservoir for crossinfection by Klebsiellae. ${ }^{1}$ We have assessed the incidence of carriage of the various gentamicinresistant enterobacteria and have estimated the duration of carriage of such strains in the intestinal tract of patients involved in the present outbreak. Furthermore these resistant strains cause urinary tract infections which are generally asymptomatic. Such infections usually remain untreated and an investigation into the persistance of chronic bacteriuria has also been undertaken.

\section{Material and methods}

The subjects investigated (149 female, 111 male) were all patients at the Royal Liverpool Hospital. In addition a proportion of the patients were also followed after discharge and on readmission to the hospital.

Samples of urine, either mid-stream or catheter specimens were examined and cultured according to standard techniques. ${ }^{8}$ The criteria for urinary tract infection were the presence of leucocytes in numbers $>12 \times 10^{6} / 1$ uncentrifuged urine and of a pure growth of $>10^{8} \mathrm{CFU} / \mathrm{l}$ urine in two or more consecutive specimens. Thereafter urine was examined and cultured at least every week. All affected patients were examined for carriage of gentamicinresistant enterobacteria by means of rectal, vaginal and oral swabs and a proportion of patients by groin, umbilical, axillary and nasal swabs. Although it is known that faecal culture is more sensitive than culture of rectal swabs on solid media, ${ }^{9}$ for the isolation of less resistant Klebsiellae, rectal swabs were used in the present survey as preliminary experiments had revealed that this method was as sensitive as faecal culture for the detection of carriage of gentamicin-resistant strains or its cessation (data not shown). Vaginal swabs were taken without the aid of a speculum and were therefore also sampling the vulva and the vaginal introitus. The swabs were taken to the laboratory in transport medium and inoculated on to Petri dishes ( $9 \mathrm{~cm}$ diameter) containing MacConkey agar (Oxoid CM7B, Basingstoke, Hants) and the same incorporating gentamicin $(4 \mathrm{mg} / \mathrm{l})$. The plates were incubated aerobically at $37^{\circ} \mathrm{C}$ and examined after $24 \mathrm{~h}$ and $48 \mathrm{~h}$. If no growth was observed on both plates a further set of swabs was obtained. Colonies that grew on the gentamicin plates were tentatively identified by inoculation into Donovan's medium ${ }^{10}$ and urea broths, and finally identified using the API 20E system (API Products Ltd). Using a controlled disc sensitivity testing method ${ }^{11}$ on Diagnostic Sensitivity agar (Oxoid), the majority of isolates were resistant to tobramycin $(10 \mu \mathrm{g})$, gentamicin $(10 \mu \mathrm{g})$, neomycin $(10 \mu \mathrm{g})$, streptomycin $(10 \mu \mathrm{g})$, spectinomycin $(50 \mu \mathrm{g})$, ampicillin $(30 \mu \mathrm{g})$, cephaloridine $(30 \mu \mathrm{g})$, sulphamethoxazole $(50 \mu \mathrm{g})$, trimethoprim $(2.5 \mu \mathrm{g})$, tetracycline $(10 \mu \mathrm{g})$ and chloramphenicol $(25 \mu \mathrm{g})$. Resistance to all the antibiotics listed above was transferable en bloc to $E$ coli $(\mathrm{K} 12)$ from each of the 95 strains tested. Klebsiellae were subjected to capsular serotyping by Coventry PHLS using counter-immunoelectrophoresis (CIE), ${ }^{12}$ and the identity of serotypes $\mathrm{K} 2, \mathrm{~K} 39, \mathrm{~K} 43, \mathrm{~K} 47$ and $\mathrm{K} 68$ were confirmed in our laboratory using both CIE and "Quellung" reactions. ${ }^{13}$ To establish that a patient was no longer harbouring gentamicinresistant enterobacteria, three consecutive sets of negative specimens including at least one faecal sample were required.

Statistical analysis was carried out using the $\chi^{2}$ test (with Yates' correction where applicable) and Student's $t$ test.

\section{Results}

\section{CARRIAGE}

The mean incidence of carriage of gentamicinresistant enterobacteria (Table 2) was obtained on patients carrying such strains at any one site on two or more occasions. Of the 260 patients involved in the outbreak $217(83.5 \%)$ showed intestinal carriage. Excretion from the intestinal tract was significantly less sporadic than from any other site. However intestinal carriage of gentamicin-resistant enterobacteria was dependent upon the genus involved (Table 3). Patients affected by gentamicin-resistant strains of Citrobacter were significantly less likely to carry such strains in their intestinal tracts than patients harbouring similarly resistant strains of $E$ coli or Klebsiellae.

Table 2 Mean incidence of carriage

\begin{tabular}{lcll}
\hline Site & $\begin{array}{l}\text { No of } \\
\text { patients }\end{array}$ & Mean incidence index $\pm S D$ & $p$ \\
\hline Intestinal tract & 172 & $0.92 \pm 0.21$ & - \\
Vagina & 61 & $0.75 \pm 0.39$ & - \\
Mouth & 172 & $0.30 \pm 0.39$ & $<0.001$ \\
Groin & 38 & $0.53 \pm 0.46$ & $<0.001$ \\
Umbilicus & 18 & $0.22 \pm 0.38$ & $<0.001$ \\
Axillae & 23 & $0.10 \pm 0.28$ & $<0.001$ \\
Nose & 27 & $0.02 \pm 0.08$ & $<01$ \\
\hline
\end{tabular}

The results are expressed as the mean incidence of carriage \pm the standard deviation. $p$ is the probability that the incidence index was less than that for the intestinal tract. The incidence of carriage for each patient was obtained by dividing the numbers of positive specimens by the number of specimens taken at any one site. The values from each site for all patients were summed and a mean incidence index obtained. 
Table 3 Intestinal carriage of gentamicin-resistant enterobacteria

\begin{tabular}{lcclll}
\hline Organism & No tested & $\begin{array}{l}\text { No carrying on } \\
\text { one or more } \\
\text { occasions }\end{array}$ & $\%$ & $p \dagger$ \\
\hline Klebsiella spp & 227 & 197 & 86.8 & - \\
$\begin{array}{l}\text { E coli } \\
\text { Citrobacter spp }\end{array}$ & 41 & 32 & 78 & NS \\
$\begin{array}{l}\text { Enterobacter spp } \\
\text { Proteus/ }\end{array} \quad 12$ & 10 & 8 & 40 & $<0.001$ \\
$\quad$ Providencia spp & 4 & 2 & 56.7 & NS \\
\hline
\end{tabular}

*Some patients harboured more than one gentamicin-resistant species of enterobacteria.

$\nmid p$ is the probability (by $\chi^{2}$ test) that the organism was less likely to be isolated from the intestinal tract than Klebsiellae.

NS = not significant.

Vaginal swabs were positive from 49 out of 68 patients tested $(72 \%)$ but the incidence of isolation was more sporadic than from the intestinal tract. However on direct comparison of 209 sets of rectal and vaginal swabs from 49 patients it was found that both swabs were positive on the majority of occasions $(68 \%)$. On 36 occasions $(17 \cdot 2 \%)$ rectal swabs were positive and vaginal swabs were negative and on 31 occasions $(14.8 \%)$ vaginal swabs were positive whilst rectal swabs were negative. The women showing vaginal carriage were older (mean age $74.5 \pm 14.5 \mathrm{yr}$ ) than those not showing such carriage (mean age $56.9 \pm 20.7 \mathrm{yr}$ ), and this difference was statistically significant $(t=4.52 \mathrm{p}$ $<0.001)$. In addition a greater proportion $(67 \%)$ of the patients showing vaginal carriage were bedridden than the proportion not showing vaginal carriage $(37 \%)$. This difference was also statistically significant $\left(\chi^{2} 5.26 \mathrm{p}<0.05\right)$. However factors other than those ascribable to the patients were involved. Forty-seven of 58 patients $(81 \%)$ affected by gentamicin-resistant Klebsiellae showed vaginal carriage whereas only two of eight $(25 \%)$ showed vaginal carriage of gentamicin-resistant strains of Citrobacter. This difference was statistically significant ( $\chi^{2}$ with Yates' correction, 8.8, $\left.\mathrm{p}<0.01\right)$. No such difference was apparent on comparing the proportions of patients showing vaginal carriage of gentamicin-resistant strains of Klebsiellae (81\%) and E coli $(5 / 7 ; 71 \cdot 4 \%)$.

Oral swabs were positive on one or more occasions from only 77 of 217 patients tested $(35.5 \%)$ and carriage at this site was sporadic (Table 2). In the present outbreak 34 of the 77 patients $(44 \%)$ showing oral carriage subsequently died in hospital (mostly of causes unrelated to this carriage) whereas only 10 of the 130 patients not showing oral carriage $(7.7 \%)$ died in hospital. Thus indicating that moribund patients were more likely $\left(\chi^{2} 42 \cdot 1\right.$, $\mathrm{p}<0.001)$ to show oral carriage of gentamicin- resistant enterobacteria than other patients.

The incidence of carriage of gentamicin-resistant enterobacteria at skin sites was dependent upon their distance from the perineum (Table 2). The groin was positive for $61 \%(22 / 36)$ patients, the umbilicus for $33 \%(6 / 18)$, the axillae for $12.5 \%(3 / 24)$ and the anterior nares for $4.5 \%(1 / 22)$ of patients.

Since carriage of gentamicin-resistant enterobacteria was least sporadic in the intestinal tract, the duration of carriage of each of the different enterobacteria at this site was chosen for further study. Table 4 shows the time taken for loss of intestinal

Table 4 Loss of carriage of gentamicin-resistant enterobacteria

\begin{tabular}{|c|c|c|c|c|}
\hline \multirow[t]{2}{*}{ Organism } & \multicolumn{2}{|c|}{ Patients losing carriage } & \multicolumn{2}{|c|}{ Patients not losing carriage } \\
\hline & No & $\begin{array}{l}\text { Time taken } \\
(\text { days }) \pm S D\end{array}$ & No & $\begin{array}{l}\text { Mean study time } \\
\text { (days) }\end{array}$ \\
\hline \multicolumn{5}{|l|}{ Klebsiella } \\
\hline spp & 43 & $39.5 \pm 34.4$ & 154 & 40 \\
\hline $\begin{array}{l}\text { E coli } \\
\text { Citrobacter }\end{array}$ & 8 & $40.9 \pm 47.4$ & 24 & 29.9 \\
\hline spp & 7 & $18.7 \pm 19.9$ & 3 & $9 \cdot 7$ \\
\hline Enterobacter & & & & \\
\hline spp & 2 & $17 \cdot 5$ & 6 & $33 \cdot 7$ \\
\hline
\end{tabular}

carriage for each of the different gentamicinresistant enterobacteria, and the mean duration of study for those not losing such carriage. Forty-three $(22 \%)$ of 197 patients carrying gentamicin-resistant klebsiellae in their intestinal tract lost such carriage and eight of $32(25 \%)$ lost carriage of similarly resistant strains of $E$ coli. In contrast, seven of 10 patients $(70 \%)$ lost carriage of gentamicin-resistant strains of Citrobacter. Thus indicating that gentamicin-resistant strains of Citrobacter were significantly less able to become established as part of the intestinal flora than similarly resistant strains of Klebsiellae ( $\chi^{2}$ with Yates' correction 9.6, $\mathrm{p}<0.01$ ) or $E$ coli ( $\chi^{2}$ with Yates' correction $4.9, \mathrm{p}<0.05$ ). With respect to intestinal carriage Klebsiellae did not form a homogeneous group. Intestinal carriage of gentamicin-resistant Klebsiella oxytoca was lost from 5 of 11 patients $(46 \%)$ whereas carriage of other resistant Klebsiellae was lost from only 38 of 186 patients $(20 \%)$. In addition the time taken for loss of intestinal carriage of Klebsiella oxytoca $(9 \cdot 4 \pm 7 \cdot 3$ days) was significantly shorter than for other Klebsiellae (43.4 \pm 34.6 days) $(t=2.1 \mathrm{p}<0.05)$. Although on average patients who did not lose intestinal carriage were studied for longer than patients who lost carriage, not all patients were studied for long periods and this may give a falsely low estimate of the rate of loss of carriage of such organisms. In order to circumvent this difficulty the 
patients who lost intestinal carriage were divided into cohorts depending on the ten-day period in which they lost carriage. The numbers losing carriage in each ten-day period were then expressed as a proportion of the patients who were studied during that ten-day period or longer. Table 5 shows the result of such an analysis for loss of intestinal carriage of Klebsiellae. The rate of loss was uniform for each of the ten-day periods and gave a mean rate of loss of $6.8 \pm 3.1 \%$ for each period. This represents a half-life of carriage of gentamicinresistant Klebsiellae of approximately 100 days. In addition three patients carried gentamicin-resistant Klebsiellae in their intestinal tracts for over 200 days. This analysis was also carried out for gentamicinresistant $E$ coli (data not shown) and a similar pattern was obtained with some patients showing carriage for over 150 days. The mean rate of loss of carriage was $4.8 \pm 6.5 \%$ of patients for each ten-day period. It was not possible to carry out such an analysis for gentamicin-resistant strains of Citrobacter as the numbers of patients (10) showing intestinal carriage was small. However the majority (6) of patients lost carriage rapidly ( $<5$ days) and no patient showed carriage for longer than 60 days.

Table 5 Loss of carriage of gentamicin-resistant Klebsiellae

\begin{tabular}{llcc}
\hline $\begin{array}{l}\text { Period of } \\
\text { observation }\left(\text { days }^{*}\right)\end{array}$ & $\begin{array}{l}\text { No of patients } \\
\text { studied }\end{array}$ & $\begin{array}{l}\text { No of patients } \\
\text { losing carriage }\end{array}$ & $\%$ \\
\hline $1-10$ & 192 & 8 & $4 \cdot 2$ \\
$11-20$ & 129 & 6 & $4 \cdot 7$ \\
$21-30$ & 91 & 10 & 11 \\
$31-40$ & 65 & 3 & $4 \cdot 6$ \\
$41-50$ & 55 & 2 & $3 \cdot 6$ \\
$51-60$ & 36 & 4 & $11 \cdot 1$ \\
$61-70$ & 36 & 2 & $5 \cdot 6$ \\
$71-80$ & 25 & 3 & 12 \\
$81-90$ & 20 & 1 & 5 \\
$91-100$ & 16 & 1 & $6 \cdot 3$ \\
$101-150$ & 15 & 3 & 20 \\
$151-200$ & 6 & 0 & 0 \\
$>200$ & 3 & 0 & 0 \\
\hline
\end{tabular}

*From first positive specimen.

Finally of the 43 patients who ceased intestinal carriage of gentamicin-resistant Klebsiellae only five were found to be carrying less resistant Klebsiellae and none of the seven serotypes isolated from these patients was the same as the original gentamicinresistant strains. This suggests that the cessation of carriage was due to loss of the organism and its plasmid rather than a shedding of the plasmid by the organism.

INFECTION

The various gentamicin-resistant enterobacteria were each able to provide laboratory evidence of urinary tract infection but did not always produce clinical manifestations (only $21 \%$ of cases were symptomatic). Most of the patients remained untreated for long periods. Spontaneous clearance of the urine did occur in the absence of antibiotic therapy but was dependent upon the strains of enterobacteria involved. Table 6 shows the numbers of patients who spontaneously lost infection and the time taken for this to occur, and compares this data with the duration of study for patients not showing spontaneous clearance of their urinary tracts. A greater proportion of patients infected with gentamicinresistant species of Citrobacter showed spontaneous clearance $(50 \%)$ than those infected by gentamicinresistant Klebsiellae $(21.2 \%)$ and this difference was statistically significant ( $\chi^{2}$ with Yates' correction 4.28, $\mathrm{p}<0.05$ ). Again Klebsiellae did not form a homogeneous group. Of seven patients infected with gentamicin-resistant strains of Klebsiellae oxytoca, five $(71 \%)$ spontaneously lost these organisms from their urinary tracts, whereas of 125 patients infected with other Klebsiellae only $23(18.4 \%)$ showed spontaneous clearance. This difference is statistically significant ( $\chi^{2}$ with Yates' correction $8 \cdot 2, p<0.01$ ). Although infections due to Citrobacter were cleared more rapidly than those due to Klebsiellae (Table 6), the difference was not statistically significant.

\section{Table 6 Clearance and persistence of bacteriuria}

\begin{tabular}{|c|c|c|c|c|}
\hline \multirow[t]{2}{*}{ Organism } & \multicolumn{2}{|c|}{ Bacteriuria ceased } & \multicolumn{2}{|c|}{ Bacteriuria persisted } \\
\hline & $\begin{array}{l}\text { No of } \\
\text { patients }\end{array}$ & $\begin{array}{l}\text { Mean time } \\
(\text { days }) \pm S D\end{array}$ & $\begin{array}{l}\text { No of } \\
\text { patients }\end{array}$ & $\begin{array}{l}\text { Mean study time } \\
\text { (days) }\end{array}$ \\
\hline \multicolumn{5}{|l|}{ Klebsiella } \\
\hline spp & 28 & $24 \pm 32 \cdot 8$ & 104 & $28 \cdot 2$ \\
\hline$E$ coli & 2 & $12 \cdot 5$ & 8 & $42 \cdot 8$ \\
\hline $\begin{array}{l}\text { Citrobacter } \\
\text { spp }\end{array}$ & 7 & $9 \cdot 7 \pm 9 \cdot 1$ & 7 & $2 \cdot 3$ \\
\hline
\end{tabular}

A similar analysis to that shown in Table 5 was carried out on those patients with urinary tract infections due to gentamicin-resistant Klebsiellae (Table 7). The rate of clearance was less uniform than for loss of rectal carriage, however a mean rate of loss of $3.7 \pm 3.8 \%$ of the patients for each ten-day period was obtained (a half-life of 180 days). In addition three patients had chronic bacteriuria that persisted for over $\mathbf{2 0 0}$ days, and one for over $\mathbf{5 8 0}$ days. The number of patients with chronic bacteriuria due to gentamicin-resistant strains of $E$ coli and Citrobacter was too small for such an analysis. However two patients had chronic bacteriuria due to $E$ coli that persisted for over 100 days. In contrast in the majority of cases bacteriuria due to gentamicinresistant Citrobacter did not persist beyond 30 days 
Table 7 Bacteriuria due to gentamicin-resistant Klebsiellae

\begin{tabular}{lllc}
\hline $\begin{array}{l}\text { Period studied } \\
\left.\text { (days }{ }^{*}\right)\end{array}$ & $\begin{array}{l}\text { No of patients } \\
\text { studied }\end{array}$ & $\begin{array}{l}\text { No of patients showing } \\
\text { spontaneous clearance }\end{array}$ & $\%$ \\
\hline $1-10$ & 155 & 13 & $8 \cdot 4$ \\
$11-20$ & 86 & 5 & $5 \cdot 8$ \\
$21-30$ & 49 & 4 & $8 \cdot 2$ \\
$31-40$ & 33 & 3 & $9 \cdot 1$ \\
$41-50$ & 25 & 0 & 0 \\
$51-60$ & 18 & 1 & $5 \cdot 6$ \\
$61-70$ & 14 & 0 & 0 \\
$71-80$ & 13 & 0 & 0 \\
$81-90$ & 12 & 0 & 0 \\
$91-100$ & 12 & 0 & 0 \\
$101-150$ & 9 & 2 & $22 \cdot 2$ \\
$151-200$ & 7 & 0 & 0 \\
$>200$ & 4 & 0 & 0 \\
\hline
\end{tabular}

*From first positive specimen.

and only one patient showed chronic bacteriuria of over 40 days.

\section{Discussion}

\section{SITE OF CARRIAGE}

The intestinal tract provided a good reservoir for gentamicin-resistant enterobacteria, an observation that has been made previously for less resistant Klebsiellae. ${ }^{1}$ Excretion of such organisms from this site was significantly less sporadic than from any other site and was present on almost every occasion that the patients were sampled (mean incidence index 0.92). This finding gives additional support to our preliminary experiments which showed that rectal swabs cultured on selective solid media were as sensitive as faecal culture for detecting gentamicinresistant enterobacteria. If rectal swabs were not sufficiently sensitive the excretion would have appeared far more sporadic.

Although it is known that the vaginal flora can vary especially during the use of the contraceptive "pill" or after the menopause little attention has been paid to vaginal carriage of Klebsiellae. ${ }^{14}$ This site formed the second largest reservoir of gentamicinresistant enterobacteria and on direct comparison with rectal swabs taken from the same patients at the same time was as frequently positive. This could be of importance in the development of urinary tract infections as the site is so close to the urethra.

During the outbreaks reported from London ${ }^{3}$ and from Bristol ${ }^{4}$ oral carriage of gentamicin-resistant Klebsiellae was noted in $25 \%$ of 16 patients and $10 \%$ of 29 patients respectively. These proportions are lower than the $35.5 \%$ (of 217 patients) in the present outbreak. However, neither of the former reports indicated the number of times that patients were sampled. The presence of gentamicin-resistant enterobacteria in the mouth was highly sporadic (mean incidence index 0.30 ) and it is conceivable that a sample taken on one occasion only could lead to a falsely low estimate of oral carriage. The observation that moribund patients were more likely to show oral carriage of gentamicin-resistant enterobacteria confirms and extends earlier reports $^{115}$ on less resistant strains.

\section{DURATION}

Gentamicin-resistant strains of $E$ coli, Klebsiellae (not Klebsiella oxytoca) and Enterobacter were more likely to be carried in the intestinal tract, vagina and mouths of affected patients than similarly resistant strains of Citrobacter. Indeed when gentamicinresistant strains of Citrobacter or Klebsiella oxytoca were isolated from the intestinal tract, carriage was not prolonged, suggesting that the intestinal tract did not provide a reservoir for cross-infection with these strains. In contrast excretion of gentamicin-resistant strains of $E$ coli and Klebsiellae persisted for long periods (half-lives of 140 days and 100 days respectively). The concept of half-life for carriage of these strains whilst implying a regularity that the process does not possess, does provide a measure of the duration of carriage. It also indicates that the resistance plasmid coexists well with its host organism, even in the absence of antibiotic therapy. In addition patients who were removed from the hospital environment were as prone to show persistence of carriage of resistant enterobacteria as those who remained in hospital (data not shown). When carriage of gentamicin-resistant Klebsiellae ceased both the host organism and the plasmid were lost thus providing further evidence of the stability of the plasmid.

\section{INFECTION}

Gentamicin-resistant strains of Klebsiellae (other than Klebsiella oxytoca) and $E$ coli were excreted in the urine for long periods. In contrast similarly resistant strains of Klebsiella oxytoca, Citrobacter and Enterobacter were rapidly cleared from the urine generally following removal of an in-dwelling urinary catheter. Thus another reservoir of infection is provided by patients infected with gentamicinresistant strains of $E$ coli and Klebsiellae. Perhaps of greater significance is the fact that simple procedures such as insertion or removal of in-dwelling urinary catheters or even straining to micturate following removal of a catheter can lead to bacteraemia ${ }^{16}$ and the longer that bacteriuria persists the greater is the chance of this occurrence. In addition it has been demonstrated that elderly patients with chronic bacteriuria have their life expectancy decreased by $30 \%-50 \%{ }^{17}$ These factors must be weighed against the possibility of development of further resistance ${ }^{18}$ 
in deciding whether to treat such patients.

Gentamicin-resistant Klebsiellae (other than Klebsiella oxytoca) are well fitted for cross-infection as they survive well on skin and on drying, ${ }^{7}$ become part of the intestinal flora and produce chronic bacteriuria. Gentamicin-resistant strains of $E$ coli are fitted for autoinfection as they readily become established in the intestinal and urinary tracts but are less well fitted for cross-infection since they do not survive well on skin or on drying. ${ }^{7}$ Finally, gentamicin-resistant strains of Citrobacter are poorly fitted for both cross-infection and autoinfection as they are not easily established in the intestinal tract and do not survive well on skin or on drying. ${ }^{\text {? }}$

We would like to thank Dr P Mortimer (Coventry PHLS) for undertaking the serotyping of the Klebsiellae and Professor EM Cooke (University of Leeds) for providing capsular antisera.

\section{References}

${ }^{1}$ Selden R, Lee BA, Wang WLC, Bennett JV, Eickhoff TC. Nosocomial Klebsiella infections: intestinal colonization as a reservoir. Ann Intern Med 1971;74:657-64.

${ }^{2}$ Cooke EM, Pool R, Brayson JC, Edmonson AS, Munro ME, Shinebaum R. Further studies on sources of Klebsiella aerogenes in hospital patients. J Hyg (Camb) 1979;83:391-405.

${ }^{3}$ Casewell MW, Dalton MT, Webster M, Phillips I. Gentamicin-resistant Klebsiella aerogenes in a urological ward. Lancet 1977 ;ii;444-6.

${ }^{4}$ Curie K, Speller DCE, Simpson RA, Stephens M, Cooke DI. A hospital epidemic caused by a gentamicinresistant Klebsiella aerogenes. J Hyg (Camb) 1978;80: 115-23.

${ }^{5}$ Houang ET, Simms PA, Horton RA, Casewell MW. Faecal carriage of multiply-resistant Klebsiellae. Proceedings of 11 th International Congress of Chemotherapy and 19th Interscience Conference on Anti- microbial Agents and Chemotherapy 1979, Abstract 642 .

${ }^{6}$ Houang ET, Casewell MW, Simms PA, Horton RA. Hospital-acquired faecal Klebsiellae as source of multiple resistance in the community. Lancet 1980; : 148-9.

${ }^{7}$ Hart CA, Gibson MF, Buckles AM. Variation in skin and environmental survival of hospital gentamicin-resistant enterobacteria. J Hyg (Camb) 1981;87:277-85.

${ }^{8}$ Brumfitt W, Percival A, Williams JD. Estimation of bacteria and white cells in the urine. ACP Broadshee 80, 1973:1-11.

${ }^{9}$ Cooke EM, Brayson JC, Edmonson AS, Hall D. An investigation into the incidence and sources of Klebsiella infections in hospital patients. J Hyg (Camb) 1979;82: 473-80.

${ }^{10}$ Donovan TJ. A Klebsiella screening medium. J Med Lab Technol 1966;23:194-7.

${ }^{11}$ Stokes EJ, Waterworth PM. Antibiotic sensitivity tests by diffusion methods. ACP Broadsheet 1972;55:1-12.

12 Palfreyman JM. Klebsiella serotyping by counter-current immunoelectrophoresis. J Hyg (Camb) 1978;81:219-25.

${ }^{13}$ Casewell MW. Titres and cross-reactions of commercial antisera for the capsular typing of Klebsiella species. $J$ Clin Pathol 1975;28:33-6.

${ }^{11}$ Corbishley CM. Microbial flora of the vagina and cervix. $J$ Clin Pathol 1977;30:745-8.

15 Johanson WG, Pierce AK, Sanford JP. Changing pharyngeal bacterial flora of hospitalized patients. $N$ Engl J Med 1969;281:1137-40.

${ }^{16}$ Slade N. Post operative urinary tract infections in urology and gynaecology: a review. J Roy Soc Med 1980;73: 739-43.

17 Dontas AS, Kasviki-Charvati P, Papanayiotou PC, Marketos SG. Bacteriuria and survival in old age. $N$ Engl J Med 1981;304:939-43.

${ }^{18} \mathrm{Hart}$ CA, Desmond AD, Percival A. Treatment of Klebsiella urinary tract infections with cephradine, augmentin, cefuroxime and amikacin. $J$ Antimicrob Chemother 1981;8:231-7.

Requests for reprints to: Dr CA Hart, Department of Medical Microbiology, Duncan Building, Royal Liverpool Hospital, PO Box 147, Liverpool L69 3BX, England. 